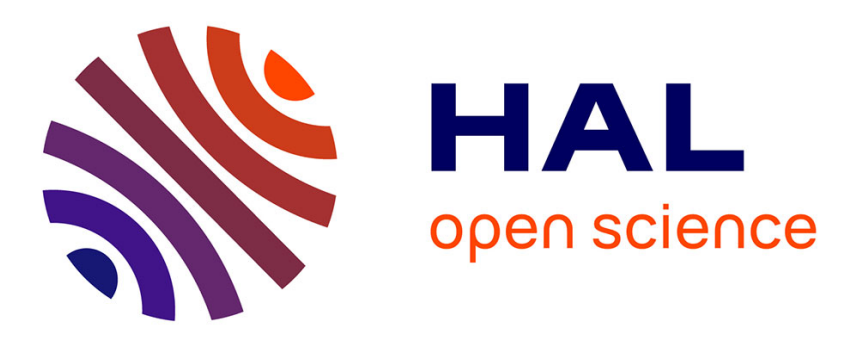

\title{
Deep surface amorphization in silicon induced by spectrally-tuned ultrashort laser pulses
}

Mario Garcia-Lechuga, Noemi Casquero, Andong Wang, David Grojo, Jan Siegel

\section{- To cite this version:}

Mario Garcia-Lechuga, Noemi Casquero, Andong Wang, David Grojo, Jan Siegel. Deep surface amorphization in silicon induced by spectrally-tuned ultrashort laser pulses. 2021 Conference on Lasers and Electro-Optics Europe \& European Quantum Electronics Conference (CLEO/Europe-EQEC), 2021, Munich, Germany. pp.1-1, 10.1109/CLEO/Europe-EQEC52157.2021.9542488 hal-03377145

\section{HAL Id: hal-03377145 \\ https://hal.science/hal-03377145}

Submitted on 14 Oct 2021

HAL is a multi-disciplinary open access archive for the deposit and dissemination of scientific research documents, whether they are published or not. The documents may come from teaching and research institutions in France or abroad, or from public or private research centers.
L'archive ouverte pluridisciplinaire HAL, est destinée au dépôt et à la diffusion de documents scientifiques de niveau recherche, publiés ou non, émanant des établissements d'enseignement et de recherche français ou étrangers, des laboratoires publics ou privés. 


\title{
Deep surface amorphization in silicon induced by spectrally-tuned ultrashort laser pulses
}

\author{
Mario García-Lechuga ${ }^{1}$, Noemi Casquero ${ }^{2}$, Andong Wang ${ }^{3}$, David Grojo ${ }^{3}$, and Jan Siegel ${ }^{2}$ \\ 1. Departamento de Física Aplicada, Universidad Autónoma de Madrid, Campus de Cantoblanco, 28049 Madrid, Spain \\ 2. Laser Processing Group, Instituto de Óptica, IO-CSIC, Serrano 121, 28006 Madrid, Spain \\ 3. Aix-Marseille University, CNRS, LP3 UMR 7341, 13009 Marseille, France
}

Irradiation of crystalline silicon with ultrashort laser pulses is a well-known method for creating thin amorphous surface layers. The underlying mechanisms are based on ultrafast melting and rapid quenching of the molten phase, preventing the formation of the crystalline phase. The interest of this method for applications in the electronics industry lies in the very different electrical properties of the amorphous phase obtained. It has also growing interest in the field of silicon photonics, the amorphous phase exhibiting a higher refractive index than the crystalline phase at telecom wavelengths. This simple feature could be exploited for low-loss optical waveguiding in a thin amorphous surface layer, provided the latter is sufficiently thick. However, the maximum thickness of laser-induced amorphous layers reported to date is $<70 \mathrm{~nm}$ [1], which is below the requirements for supporting guided modes.

We have explored a number of experimental strategies to increase the layer thickness beyond today's limit. In particular, we have employed an amplified laser system with spectral tunability from $515 \mathrm{~nm}$ to $4 \mu \mathrm{m}$ in order to perform systematic irradiation studies. Of particular interest is the underexplored mid-infrared region of the spectrum corresponding to the silicon transparency domain $(\lambda>1400 \mathrm{~nm})$. We have also investigated the differences between multiple pulse and single pulse irradiation strategies, as well as the influence of the crystal orientation of the silicon substrate. Moreover, the presence of a thick silicon dioxide cover layer was identified as a further key optimization parameter, directly influencing the heat extraction and thus melt quenching dynamics.

For an efficient exploration of the enormous parameter space and its influence on the thickness of the amorphous layer, we have employed an optical method for thickness determination, based on interference of the illumination light reflected at the front and the back surface of the amorphous layer [1,2]. We have confirmed the validity of this method by comparison with SEM microscopy of cleaved cross sections of laser-amorphized regions, as shown in Fig. 1(a,b). Our results show that with optimized parameters, amorphous layers with a maximum thickness of $128 \mathrm{~nm}$ can be achieved (c.f. Fig. 1(c)), much exceeding the mentioned $70 \mathrm{~nm}$-limit. Moreover, multiple pulse irradiation and the use of a $\mathrm{SiO}_{2}$ cover layer were found to be beneficial for the formation of thick amorphous layers.
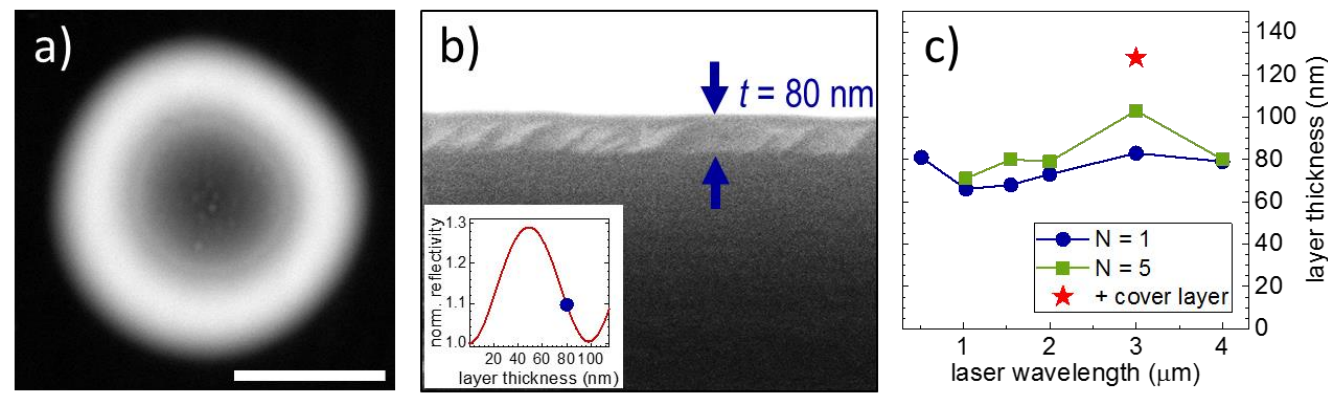

Fig. 1 (a) Optical microscopy image of an amorphous spot in crystalline silicon, formed upon exposure to a single laser pulse at $\lambda=3 \mu \mathrm{m}$. The darkening in the spot center is not caused by sample damage but a consequence of destructive interference of the illumination light reflected at the two interfaces of the amorphous surface layer. This interference effect has been modelled in the inset of (b) as a function of layer thickness (red curve). The blue data point corresponds to the experimental reflectivity value in the spot center of (a), indicating a thickness of $80 \mathrm{~nm}$. (b) SEM image of a cleaved sample cross section, revealing the presence of an amorphous layer with a thickness of $80 \mathrm{~nm}$. (c) Maximum thickness values of the laser induced amorphous layer as a function of laser wavelength, for single pulse $(\mathrm{N}=1)$ and multiple pulse $(\mathrm{N}=5)$ irradiation. The red symbol marks the maximum thickness achieved by using the presence of a silicon dioxide cover layer.

While the maximum thickness achieved in this study reamains insufficient to achieve asymmetric waveguides, it is compatible with single mode waveguiding for a symmetric waveguide configuration. Finally, we propose additional strategies for further increasing the layer thickness to enable silicon photonics based on directly written surface waveguides.

\section{References}

[1] Y. Fuentes-Edfuf, M. Garcia-Lechuga, D. Puerto, C. Florian, A. Garcia-Leis, S. Sanchez-Cortes, J. Solis, and J. Siegel, "Coherent scattercontrolled phase-change grating structures in silicon using femtosecond laser pulses," Sci. Rep. 7, 4594 (2017).

[2] J. Bonse, "All-optical characterization of single femtosecond laser-pulse-induced amorphization in silicon," Appl. Phys. A Mater. Sci. Process. 84, 63 (2006 